Philippine Journal of Psychology, 2018, 51(1), 63-80

Copyright @ 2018 Psychological Association of the Philippines

\title{
Interdependent Happiness is Associated With Higher Levels of Behavioral and Emotional Engagement Among Filipino University Students
}

\author{
Jesus Alfonso D. Datu \\ The Education University of Hong Kong \\ Gabriel Sebastian N. Lizada \\ Ateneo de Davao University
}

In collectivist societies, individuals are likely to espouse a sociallyoriented construal of happiness. Yet previous studies on the consequences of happiness and well-being have mostly concentrated on examining how a personal construal of happiness optimized positive academic and psychological outcomes. This research explored the association of interdependent happiness with the behavioral as well as the emotional domains of academic engagement and disaffection among 220 Filipino university students enrolled in a private university through a cross-sectional investigation. Results of the hierarchical regression analyses demonstrated that interdependent happiness positively predicted behavioral and emotional engagement even after controlling for demographic variables (i.e., age and gender). Interdependent happiness did not predict both behavioral and emotional disaffection. Furthermore, the effect sizes between interdependent happiness and engagement domains ranged from 'relatively small' to 'typical'. The theoretical and practical implications of the findings are discussed.

Keywords: academic engagement, disaffection, interdependent happiness

Correspondence concerning this article can be addressed to Jesus Alfonso D. Datu, The Education University of Hong Kong, D2-2F-28, 10 Lo Ping Road, Tai Po, New Territories, Hong Kong SAR China. Email: jadatu@eduhk.hk 
Positive psychology refers to the "study of the conditions and processes that contribute to the flourishing or optimal functioning of people" (Gable \& Haidt, 2005, p. 104). The positive psychology movement hopes to understand the psychological antecedents, processes, and outcomes of positive qualities, states, and institutions (Seligman \& Csikszentmihalyi, 2000). This perspective resulted in investigations that explored the personal, social, and contextual predictors of happiness and other well-being outcomes.

One line of evidence in the extant positive psychology literature points to the role that well-being plays in shaping academic outcomes. For example, previous studies have shown that life satisfaction was linked to higher levels of academic achievement (Gilman \& Huebner, 2006; Heffner \& Antaramian, 2016; Huebner, Hills, Siddall, \& Gilman, 2014; Long \& Huebner, 2014; Ng, Huebner, \& Hills, 2015; Rode et al., 2005) and engagement (Datu, 2016; Salmela-Aro \& TuominenSoini, 2010). Other studies have demonstrated that positive affect was associated with elevated levels of academic engagement (Datu, Valdez, \& King, 2017; King, McInerney, Ganotice, \& Villarosa, 2015; Lewis, Huebner, Maloner, \& Valois, 2011; Valiente, Swanson, \& Eisenberg, 2012) and achievement (Datu, 2017; Nickerson, Diener, \& Schwarz, 2011; Oishi, Diener, \& Lucas, 2007; Villavicencio \& Bernardo, 2013, 2016). These findings clearly suggest that both cognitive and emotional well-being may be associated with academic outcomes.

Even with the growing body of studies on how well-being indices can predict various indicators of academic functioning, these studies have some limitations. Previous studies have mostly concentrated on examining cross-cultural differences in happiness as well as exploring the association of Western-derived models of well-being (i.e., life satisfaction and positive affect) with a wide array of psychological outcomes (Hitokoto \& Uchida, 2015). Uchida and Ogihara (2012) have also pointed out that past research commonly relied on wellbeing measures or scales based on individualistic cultures' conception of happiness (e.g., Satisfaction with Life Scale by Diener, Emmons, Larsen, \& Griffin, 1985). Relying on Western-derived happiness models to conceptualize happiness in non-Western and interdependent societies may yield myopic insights on how happiness may catalyze academic outcomes in collectivist settings. 
Furthermore, previous studies involving Filipino samples have relied on individualistic models and measures of happiness. For instance, investigations used Western-derived emotional well-being questionnaires like the Positive and Negative Affect Schedule (Datu, 2013; King et al., 2015) and cognitive well-being scales such as Satisfaction with Life Scales (Bernardo \& Estrellado, 2014; Datu, 2013, 2014; Datu \& Mateo, 2015) to assess subjective well-being dimensions. Although the use of these Western-based well-being scales can provide a rough estimate of happiness in non-Western contexts, it is important to explore alternative models that will capture how happiness may operate in collectivist settings. Indeed, there is a need to utilize culturally-sensitive frameworks and assessment tools when exploring happiness in the Philippine context.

The construal theory of happiness (Uchida \& Ogihara, 2012) has proposed that there are two distinct approaches to conceptualize the meaning of happiness in various cultures. People in individualistic cultures (e.g., United States, France, and Germany) tend to espouse a personal construal of happiness which involves defining well-being in terms of personal achievements, expressing dispositions and preferences, as well as showing an autonomous sense of self. On the other hand, those in collectivist cultures (e.g., Japan and Philippines) are likely to espouse an interpersonal construal happiness, which involves conceptualizations of well-being based on achieving positive interpersonal relationships and meeting others' expectations. Hence, recent studies have focused on developing culturally-sensitive models of well-being, especially in non-Western contexts.

Interdependent happiness is defined as the "global subjective assessment of whether one is interpersonally harmonized with other people and connected to the collective way of well-being" (Hitokoto \& Uchida, 2015, p. 237). This happiness framework offers a concrete approach to capture the meaning of happiness in non-Western and collectivist cultural contexts. This model also features three interrelated dimensions, namely: (a) relationship-oriented happiness, which is based on an individual's desire to maintain strong social ties; (b) quiescent happiness, which pertains to meeting the expectations of social norms; and (c) ordinary happiness, which refers to one's own evaluation of accomplishments compared to others. 
The existing literature has shown that interdependent happiness was associated with positive psychological outcomes. In terms of psychological outcomes, studies have demonstrated that interdependent happiness was related to higher levels of life satisfaction and positive affect (Datu, King, \& Valdez, 2016; Hitokoto \& Uchida, 2015), flourishing (Datu, King, et al., 2016), as well as friendship satisfaction, positive relations with others, gratitude, and peaceful disengagement (Hitokoto \& Uchida, 2015). Interdependent happiness was also associated with lower levels of negative affect and interpersonal hopelessness (Hitokoto \& Uchida, 2015). These results indicate that interdependent happiness is linked to various dimensions of minimalist, subjective, and psychological well-being.

However, little is known on how interdependent happiness may be linked to academic functioning. To the best of our knowledge, only the investigation of Datu, King, and Valdez (2017) explored how interdependent happiness may relate to academic motivation (i.e., autonomous motivation), engagement, and achievement. This research demonstrated that interdependent happiness was consistently linked to academic engagement via cross-sectional and short-term longitudinal designs.

The broaden-and-build theory (Fredrickson, 1998, 2001) is a framework that can support the hypothesized positive association of interdependent happiness with academic engagement. This model posits that when an individual begins to experience well-being, the individual's thought-action repertoire can potentially expand. In turn, the broadening of individuals' thought-action repertoire enables them to build psychological, intellectual, and social resources. In the context of this research, we conceptualized interdependent happiness as a well-being state that may be linked to academic resources such as higher levels of behavioral and emotional engagement.

Previous research has demonstrated that interdependent happiness was related to elevated levels of academic engagement (Datu et al., 2017). However, this study only examined the association of interdependent happiness with students' overall academic engagement, which may provide limited insights on the relationship of interdependent happiness to different domains of academic engagement. Furthermore, these authors focused on assessing the link 
of interdependent happiness to academic engagement among Filipino secondary school students, which may provide limited insights into the correlates of interdependent happiness in other student populations (e.g., primary and university students).

Therefore, the present study investigated the link of interdependent happiness to academic engagement and disaffection among selected Filipino university students. Academic engagement refers to the quality of involvementand connection of students whereas disaffection pertains to the opposite: when students become passive, disengaged and lack effort in their academic tasks (Skinner, Kindermann, \& Furrer, 2009). Engagement has two dimensions, namely: (a) behavioral engagement, which refers to students' active involvement in academic-related tasks; and (b) emotional engagement, which pertains to students' degree of positive emotions when doing school-related activities. On the other hand, disaffection has two domains, namely; (c) behavioral disaffection, which refers to students' passive participation in schoolrelated tasks; and (d) emotional disaffection, which pertains to the extent of students' negative emotions in academic-related tasks. In particular, this research explored how interdependent happiness was related to behavioral engagement, emotional engagement, behavioral disaffection, and emotional disaffection.

Examining the association of interdependent happiness with academic engagement domains is an important research initiative because existing studies have pointed out that engagement is an essential outcome in educational as well as school psychology literature (Appleton, Christenson, Kim, \& Reschly, 2006; Fredricks, Blumenfeld, \& Paris, 2004). Past investigations also concentrated on how dispositional and emotional variables could predict academic engagement among Filipino student samples (Datu, 2016; Datu et al., 2017; Datu \& Valdez, 2016; Datu, Valdez, \& King, 2016; Datu et al., 2017). However, limited research has been conducted to explore how context-sensitive models of happiness may be related to various types of academic engagement. Exploring the link of interdependent happiness on different aspects of academic engagement will provide valuable insights on the role that culturally-sensitive forms of happiness (i.e., interdependent happiness) plays in promoting students' active involvement in school-related activities among Filipino university 
students.

In this study, we tested the following hypotheses:

Hypothesis 1: Interdependent happiness will positively predict behavioral and emotional engagement.

Hypothesis 2: Interdependent happiness will negatively predict behavioral and emotional disaffection.

\section{METHOD}

\section{Participants}

Two hundred twenty Filipino undergraduate students from a private university in a rural region in the Philippines participated in this study. The mean age of the participants was 17.24 and the standard deviation was 1.14. Majority of the participants were female (68.64\%). All the participants indicated in the consent form that they were voluntarily agreeing to participate in this research.

\section{Measures}

Academic engagement and disaffection. We used the 20item Academic Engagement and Disaffection Scale (Skinner et al., 2009) to assess the participants' perceived behavioral engagement (5 items), emotional engagement (5 items), behavioral disaffection (5 items), and emotional disaffection (5 items). Each item was rated on a 4-point Likert scale $(1=$ Not at all true and $4=$ Very true). Sample items in the subscales include: "In class, I work as hard as I can" and "I pay attention in class" (behavioral engagement); "When we work on something in class, I feel interested" and "Class is fun" (emotional engagement); "I don't try very hard at school" and "When I'm in class, my mind wanders" (behavioral disaffection); and "Class is not fun for me" and "When I'm in class, I feel bad" (emotional disaffection). The Cronbach's alpha reliability coefficients of the behavioral engagement, emotional engagement, behavioral disaffection, and emotional disaffection subscales were $.75, .70, .78$, and .75 , respectively.

Interdependent happiness. The 9-item Interdependent Happiness Scale was used to measure the participants' levels of 
interdependent happiness. The items were marked on a 5-point Likert scale $(1=$ Strongly disagree and $5=$ Strongly agree). Sample items in the scale include: "I believe that I and those around me (i.e., my friends, and classmates) are happy", "Although it is quite normal, I think that my living condition is very good", and "I believe that my life is just as happy as that of others around me". The Cronbach's alpha reliability coefficient of the scale was .82 .

\section{Data Analyses}

Descriptive, reliability, and Pearson-r correlational analyses were conducted using the Statistical Package for the Social Sciences (SPSS v.23). Then, hierarchical regression analyses were carried out to examine whether interdependent happiness would predict the academic engagement (i.e., behavioral and emotional engagement) and disaffection (i.e., behavioral and emotional disaffection) dimensions. In Step 1, age and gender were entered as a predictor of each outcome variable (i.e., behavioral engagement and behavioral disaffection) while in Step 2, interdependent happiness was entered as a predictor variable. In interpreting the effect sizes between interdependent happiness and engagement indices, we referred to the recommended guidelines of Gignac and Szodorai (2016) indicating that correlational coefficient values of .10, .20, and .30 can be interpreted as relatively small, typical, and relatively large respectively.

\section{RESULTS}

The results of descriptive, reliability, and correlational analyses are described in Table 1. All of the scores from the scales had adequate reliability coefficients. Interdependent happiness was positively associated with behavioral engagement and emotional engagement. However, interdependent happiness was not correlated with any academic disaffection dimensions. Consequently, we did not examine whether interdependent happiness would predict both behavioral and emotional disaffection. Based on the recommended cut-off values of Gignac and Szodorai (2016), the magnitude of effect sizes between interdependent happiness and engagement dimensions 


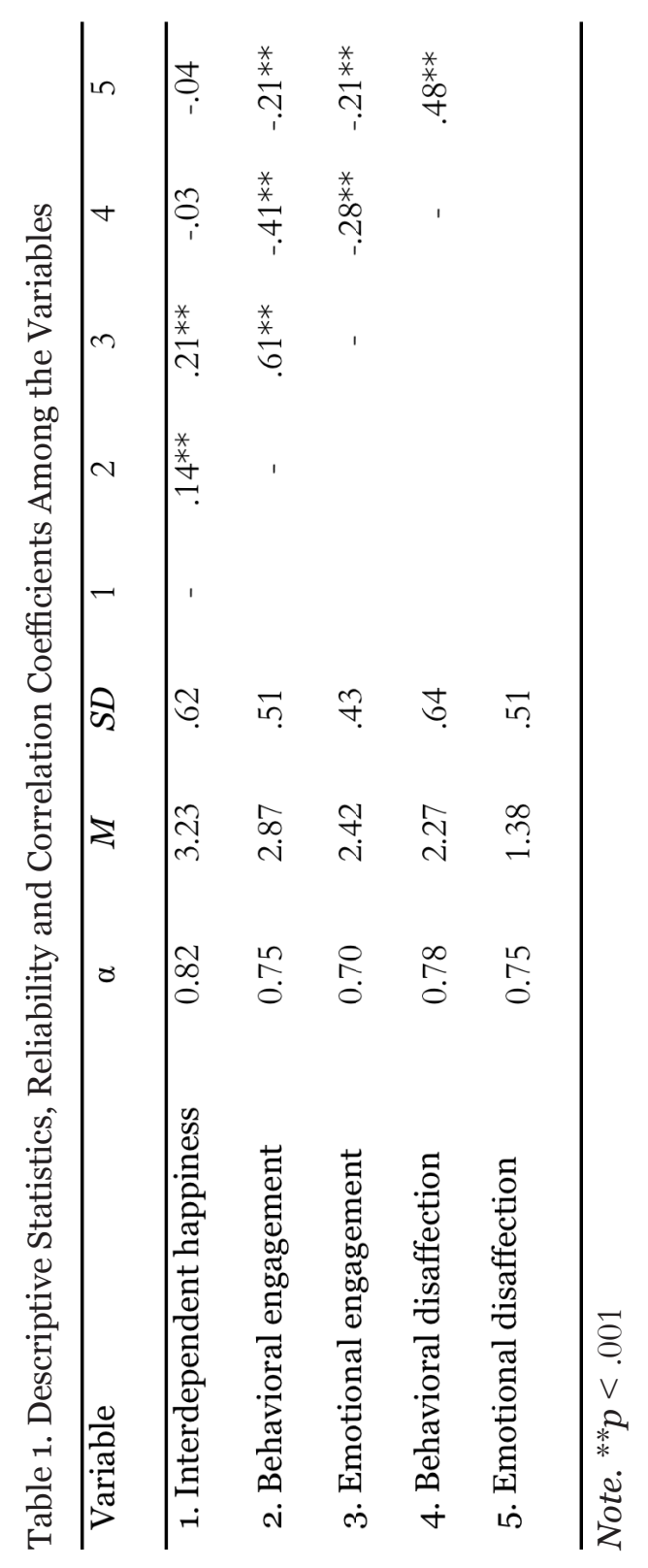


ranged from relatively small (for the link between interdependent happiness and behavioral engagement) to typical (for the association of interdependent happiness with emotional engagement).

To examine whether interdependent happiness would predict behavioral and emotional engagement after controlling for the participants' demographic variables like age and gender, we performed hierarchical regression analyses. We added age and gender as covariates because these variables can potentially influence students' engagement. Results supported Hypothesis 1 as interdependent happiness positively predicted both behavioral and emotional engagement. These findings indicate that interdependent happiness may be linked to higher levels of behavioral and emotional domains of academic engagement. The findings of hierarchical regression are shown in Table 2.

\section{DISCUSSION}

This research report aimed to examine the association of interdependent happiness with academic engagement as well as disaffection domains among Filipino university students. Findings supported our hypotheses regarding the positive correlation between interdependent happiness and different dimensions of academic engagement.

Our research demonstrated that interdependent happiness positively predicted both behavioral and emotional engagement which supported Hypothesis 1. These findings indicate that students' perceived levels of interpersonal construal of happiness may be associated with active participation and positive emotional states when performing academic-related tasks. Unlike the investigation of Datu et al. (2017) that focused on the relationship of interdependent happiness to overall academic engagement among secondary school students, our study showed that interdependent happiness might be differentially linked to academic engagement domains. Whereas Datu et al. (2017) revealed relatively large effect sizes between interdependent happiness and overall academic engagement, the effect sizes found in this research ranged from relatively small to typical between interdependent happiness as well as behavioral and 
Table 2. Hierarchical Regression Analyses of Demographic Variables and Interdependent Happiness as Predictors of Behavioral Engagement (Model 1) and Emotional Engagement (Model 2)

\begin{tabular}{|c|c|c|c|c|c|}
\hline Model & Variable & $\beta$ & $\mathrm{t}$ & $R^{2}$ & $\Delta R^{2}$ \\
\hline \multirow[t]{7}{*}{1} & Step 1 & & & .015 & .006 \\
\hline & Age & .01 & .30 & & \\
\hline & Gender & $.13^{* *}$ & 1.79 & & \\
\hline & Step 2 & & & .038 & $.023 *$ \\
\hline & Age & .003 & .086 & & \\
\hline & Gender & .15 & $1.99 *$ & & \\
\hline & Interdependent happiness & .13 & $2.27^{*}$ & & \\
\hline \multirow[t]{7}{*}{2} & Step 1 & & & .005 & .005 \\
\hline & Age & .02 & .91 & & \\
\hline & Gender & .03 & .48 & & \\
\hline & Step 2 & & & .049 & $.044 * *$ \\
\hline & Age & .02 & .63 & & \\
\hline & Gender & .05 & .93 & & \\
\hline & Interdependent happiness & $.15^{* *}$ & 3.17 & & \\
\hline
\end{tabular}

Note. Model 1 = Behavioral engagement served as the outcome variable; Model 2 = Emotional engagement served as the outcome variable. ${ }^{*} p<.05 ;{ }^{* *} p<.01 ;{ }^{* * *} p<.001$

emotional engagement respectively.

Broadly speaking, the link of interdependent happiness to academic engagement dimensions (i.e., behavioral and emotional engagement) corroborated findings from previous investigations that demonstrated a positive association between well-being states and school engagement (Datu, 2016, 2017; Heffner \& Antaramian, 2016; Lewis et al., 2011; Salmela-Aro \& Tuominen-Soini, 2010). This 
indicates that optimizing opportunities for students to experience socially-oriented happiness may be related to elevated levels of engagement outcomes among university students. To date, this is the first investigation to demonstrate that a culturally-sensitive form of happiness may be related to different aspects of students' engagement in the Philippine setting.

Results also showed that interdependent model of happiness was not associated with academic disaffection. This indicates that the extent to which individuals espouse an interpersonal construal of happiness may not be related to lack of involvement in academic-related tasks. To date, this is the first investigation that explored the association of interdependent happiness with behavioral and emotional disaffection.

Our study supported the major tenets of the broaden-andbuild theory (Fredrickson, 1998, 2001) through demonstrating that well-being states play an adaptive role in shaping different forms of resources. This research suggests that adopting an interpersonal construal of happiness characterized by relationship harmony, ordinariness, and quiescence may be linked to elevated levels of behavioral and emotional engagement. In other words, experiencing higher levels of interdependent happiness may be related to students' capacity to achieve optimal academic resources (e.g., academic engagement and achievement) in a collectivist context.

This study has a number of limitations. First, as this investigation used a cross-sectional research design, the findings may offer limited insights about the temporal precedence between interdependent happiness and academic engagement domains. Future research can address this through conducting longitudinal research designs (e.g., latent growth curve modeling approaches) to assess the association of interdependent happiness with engagement and other academic outcomes. The use of cross-lagged panel design is also a promising methodological approach to provide evidence on the reciprocal association of interdependent happiness with academic engagement. Second, this study used self-reported measures to assess students' interdependent happiness and engagement dimensions, which may be prone to common methods variance. In future studies, we recommend using alternative approaches in measuring interdependent happiness and educational outcomes. Third, our 
research only focused on examining how interdependent happiness was related to academic engagement (i.e., behavioral and emotional engagement) and disaffection (i.e., behavioral and emotional disengagement). Future research can expand this line of evidence through assessing how interdependent happiness may be linked to other indices of academic engagement like cognitive and agentic engagement. In addition, researchers are also encouraged to explore specific psychological mechanisms that may underpin the association between interdependent happiness and educational outcomes. For example, can academic self-regulation mediate the hypothesized link of interdependent happiness to academic engagement dimensions? Will academic self-efficacy underpin the association of interdependent happiness with academic outcomes?

Nonetheless, our study has theoretical implications. As interdependent happiness was linked to higher levels of behavioral and emotional engagement, this study offered some support on the potential applicability of the broaden-and-build theory (Fredrickson, 1998, 2001) in the Philippine context. The present research also extended the line of evidence on the academic correlates of interdependent happiness in a collectivist context through showing that this form of happiness may be linked to higher levels of perceived behavioral and emotional engagement. Clearly, this investigation expanded Datu et al.'s (2017) study, which only explored the association between interdependent happiness and the overall academic engagement and academic motivation among Filipino secondary school students. Our results offered a more nuanced account on how interdependent happiness differentially relates to various domains of academic engagement. However, little is known on what psychological processes may underpin the relationship of interdependent happiness to behavioral and emotional engagement. Future investigations may address this gap through identifying cognitive, emotional, and motivational mechanisms underlying thehypothesized association of interdependent happiness with different dimensions of school engagement. As this study only focused on the association of interdependent with adaptive school outcomes like emotional engagement, limited insights could be drawn on how interdependent happiness may be linked to students' mental health. Although Datu, King, et al. (2016) have demonstrated 
that interdependent happiness was linked to higher levels of positive emotions, life satisfaction, and psychological flourishing, it remains largely unknown why interdependent happiness may predict positive psychological functioning in the Philippine context. Future studies can expand this line of research through exploring process variables that may explain why an interpersonal construal of happiness may promote psychological health.

Furthermore, whereas previous research (Datu, King, et al., 2016; Datu et al., 2017) concentrated on evaluating whether interdependent happiness could predict well-being and academic outcomes among high school students in selected urban areas, this study examined how interdependent happiness was linked to engagement and disaffection among undergraduate students in a rural context in the Philippines. Findings of this study, therefore, may offer evidence on the generalizability of the hypothesized positive association between interdependent happiness and optimal educational outcomes in nonurban contexts in a collectivist setting. Moreover, it may be a promising direction to explore whether the type of cities or communities (e.g., urban vs. rural) may moderate the potential association of interdependent happiness with engagement outcomes. For example, do students in rural communities benefit more from espousing interdependent happiness than those living in urban settings? In addition, whereas previous studies consistently explored the potential benefits of interdependent happiness in different contexts (e.g., Japan and Philippines), it is also possible that espousing high levels of interdependent happiness may be linked to maladaptive outcomes. For instance, what is the likelihood that interdependent happiness will promote social approval goals and other extrinsic motivational orientations? Can interdependent happiness thwart the fulfillment of the basic psychological needs for autonomy? Indeed, future researchers can also examine the "dark side" of interdependent happiness in the Philippine context.

Furthermore, our investigation offers a few implications for practitioners in the school context. Psychologists, counselors, and mental health practitioners are encouraged to conceptualize and design psychological interventions that may cultivate students' interdependent happiness in the Philippine context. Instead of 
developing activities that may foster common dimensions of students' well-being (e.g., life satisfaction and positive emotions), mental health professionals can consider formulating activities that might promote harmonious interpersonal relationships, behaviors that corroborate the existing social norms, and achieving levels of performance that are comparable with others' accomplishments. School psychologists and counselors may consider designing psychoeducational interventions that aim to foster students' sense of connectedness to parents, teachers, and peers. Teachers are also recommended to design learning activities that may provide an opportunity for students to experience a sense of connectedness with other students so that they could demonstrate higher levels of task engagement. Furthermore, university administrators like the dean of student affairs or the director of the counseling center are encouraged to invest in nonacademic programs that aim to boost students' levels of happiness and other strategic initiatives that prioritize acquisition of essential noncognitive abilities and life skills among university students. Taken together, administrators, academic staff, and non-academic staff are encouraged to work together in developing a sustainable architecture for promoting interdependent happiness among students in the university context.

\section{Conclusion}

Recent studies have highlighted cross-cultural differences in the meaning of happiness. However, the extant literature primarily focused on exploring how individualistic and Western-derived models of well-being may promote academic outcomes in collectivist settings. This research report contributes to this line of evidence through demonstrating that interdependent happiness may be differentially linked to academic engagement domains among Filipino university students. Although this study has provided evidence on the association of interdependent happiness with behavioral and emotional engagement, more studies are warranted to determine how and why an interpersonal construal of happiness may predict different dimensions of academic engagement. The findings of this research, in general, point to the significance of exploring the correlates of 
culturally-sensitive models of well-being in the Philippine setting. Indeed, future investigations are recommended to explore how context-sensitive frameworks of happiness may influence academic functioning and psychological health to advance the science of wellbeing in the Philippines and other collectivist societies.

\section{REFERENCES}

Appleton, J. J., Christenson, S. L., Kim, D., \& Reschly, A. L. (2006). Measuring cognitive and psychological engagement: Validation of the Student Engagement Instrument. Journal of School Psychology, 44, 427-445.

Bernardo, A. B. I., \& Estrellado, A. F. (2014). Measuring hope in the Philippines: Validating the short version of the Locus-of-Hope Scale in Filipino. Social Indicators Research, 119, 1649-1661.

Datu, J. A. D. (2013). Can happiness boost self-worth? Exploring the impact of subjective well-being on the global self-esteem. Journal of Asia Pacific Counseling, 3(2), 131-138.

Datu, J. A. D. (2014). Forgiveness, gratitude, and subjective wellbeing among Filipino adolescents. International Journal for the Advancement of Counselling, 36(3), 262-273.

Datu, J. A. D. (2016). Flourishing is associated with higher academic achievement and engagement in Filipino undergraduate and high school students. Journal of Happiness Studies. Advance online publication. http://dx.doi.org/10.1007/s10902-016-9805-2

Datu, J. A. D. (2017). Peace of mind, academic motivation, and academic achievement in Filipino high school students. Spanish Journal of Psychology. Advance online publication. https://doi. org/10.1017/sjp.2017.19

Datu, J. A. D., King, R. B., \& Valdez, J. P. M. (2016). The benefits of socially-oriented happiness: Validation of the Interdependent Happiness Scale in the Philippines. Child Indicators Research, 9, 631-649.

Datu, J. A. D., King, R., \& Valdez, J. .P. M., (2017). The academic rewards of social-oriented happiness: Interdependent happiness promotes academic achievement. Journal of School Psychology, 
61, 19-31.

Datu, J. A. D., \& Mateo, N. J. (2015). Gratitude and life satisfaction among Filipino adolescents: The mediating role of meaning in life. International Journal for the Advancement of Counselling, 37(2), 198-206.

Datu, J. A. D., \& Valdez, J.P.M. (2016). Psychological capital predicts academic engagement and well-being in Filipino high school students. The Asia Pacific Education Researcher, 25(3), 399-405.

Datu, J. A. D., Valdez, J. P. M., \& King, R. B. (2016). Perseverance counts but consistency does not! Validating the Short-Grit Scale in a collectivist setting. Current Psychology, 35(1), 121-130.

Datu, J. A. D., Valdez, J. P. M., \& King, R. B. (2017). Exploring the association between peace of mind and academic engagement: Cross-sectional and cross-lagged panel studies in the Philippine context. Journal of Happiness Studies. Advance online publication. doi:10.1007/s10902-017-9902-x.

Diener, E., Emmons, R. A., Larsen, R. J., \& Griffin, S. (1985). The Satisfaction With Life Scale. Journal of Personality Assessment, 49, 71-75.

Fredericks, J. A., Blumenfeld, P. C., \& Paris, A. H. (2004). School engagement: Potential of the concept, state of the evidence. Review of Educational Research, 74, 59-109.

Fredrickson, B. (1998). What good are positive emotions? Review of General Psychology, 2, 300-319.

Fredrickson, B. L. (2001). The role of positive emotions in positive psychology: The broaden-and-build theory of positive emotions. American Psychologist, 56, 218-226.

Gable, S. L., \& Haidt, J. (2005). What (and why) is Positive Psychology? Review of General Psychology, 9, 103-110.

Gignac, G. E., \& Szodorai, E. (2016). Effect size guidelines for individual differences researchers. Personality and Individual Differences, 102, 74-78.

Gilman, R., \& Huebner, E. S. (2006). Characteristics of adolescents who report very high life satisfaction. Journal of Youth and Adolescence, 35, 311-319.

Heffner, A. L., \& Antaramian, S. P. (2016). The role of life satisfaction in predicting student engagement and achievement. Journal of 
Happiness Studies, 17, 1681-1701.

Hitokoto, H., \& Uchida, Y. (2015). Interdependent happiness: Theoretical importance and measurement validity. Journal of Happiness Studies, 16, 211-239.

Huebner, E. S., Hills, K. J., Siddall, J., \& Gilman, R. (2014). Life satisfaction and schooling. In M. Furlong, R. Gilman, \& E. S. Huebner (Eds.), Handbook of positive psychology in the schools (2nd ed., pp. 192-208). New York, NY: Routledge.

King, R. B., McInerney, D. M., Ganotice, F. A., \& Villarosa, J. B. (2015). Positive affect catalyzes academic engagement. Learning and Individual Differences, 39, 64-72.

Lewis, A. D., Huebner, E. S., Malone, P. S., \& Valois, R. F. (2011). Life satisfaction and student engagement in adolescents. Journal of Youth and Adolescence, 4O, 249-262.

Long, R. F., \& Huebner, E. S. (2014). Differential validity of global and domain-specific measures of life satisfaction in the context of schooling. Child Indicators Research, 7, 671-694.

Ng, Z. J., Huebner S., \& Hills K. (2015). Life satisfaction and academic performance in early adolescents: Evidence for reciprocal association. Journal of School Psychology. 53, 479-491.

Nickerson, C., Diener, E., \& Schwarz, N. (2011). Positive affect and college success. Journal of Happiness Studies, 12(4), 717-746.

Oishi, S., Diener, E., \& Lucas, R. E. (2007). The optimum level of wellbeing: Can people be too happy? Perspectives on Psychological Science, 2, 346-360.

Rode, J., Arthaud-Ray, M., Mooney, C., Near, J., Baldwin, T., Bommer, W., \& Rubin R. (2005). Life satisfaction and student performance. Academy of Management Learning and Education, 4, 421-433.

Salmela-Aro, K. \& Tuominen-Soini, H. (2010). Adolescents' life satisfaction during the transition to post-comprehensive education: Antecedents and consequences. Journal of Happiness Studies, 11, 683-701.

Skinner, E. A., Kindermann, T.A., \& Furrer, C. (2009). A motivational perspective on engagement and disaffection: Conceptualization and assessment of children's behavioral and emotional participation in academic activities in the classroom. Educational and Psychological Measurement, 69, 493-525. 
Seligman, M. E. P., \& Csikszentmihalyi, M. (2000). Positive psychology: An introduction. American Psychologist, 55, 5-14.

Uchida, Y., \& Ogihara, Y. (2012). Personal or interpersonal construal of happiness: A cultural psychological perspective. International Journal of Wellbeing, 2, 354-369.

Valiente, C., Swanson, J., \& Eisenberg N. (2012). Linking students' emotions and academic achievement: When and why emotions matter. Child Development Perspectives, 6, 129-135.

Villavicencio, F., \& Bernardo, A., (2013). Positive academic emotions moderate the relationship between self-regulation and academic achievement. British Journal of Educational Psychology, 83, 329-340.

Villavicencio, F. T., \& Bernardo, A. B. I. (2016). Beyond math anxiety: Positive emotions predict mathematics achievement, self-regulation and self-efficacy. The Asia-Pacific Education Researcher, 25, 415-422. 